\title{
Correction to: Chatter stability prediction for high-speedmilling through a novel experimental-analytical approach
}

\author{
N. Grossi ${ }^{1} \cdot$ F. Montevecchi ${ }^{1} \cdot$ L. Sallese $^{1} \cdot$ A. Scippa ${ }^{1} \cdot$ G. Campatelli $^{1}$
}

Published online: 7 March 2018

(C) Springer-Verlag London Ltd., part of Springer Nature 2018

Correction to: Int J Adv Manuf Technol (2017) 89:2587-

2601.

https://doi.org/10.1007/s00170-016-9832-5

The original version of this article contained graphics mistakes in some figures, occurred in the publishing process. Thus this "Erratum" is presented to fix these errors, providing the correct figures. In the caption of Fig. 4 , " $!_{c}=!_{n}$ eq." is not correct, the correct caption is " $\omega_{\mathrm{c}}=\omega_{\mathrm{n}}$ eq.". In Figs. 8, 10, 11, 13, and 15 the reference "stationary Stability Lobe Diagram (SLD)" is not visible. The correct figures are shown below.

The online version of the original article can be found at https://doi.org/ 10.1007/s00170-016-9832-5

N. Grossi

niccolo.grossi@unifi.it

1 Department of Industrial Engineering, University of Firenze, via di Santa Marta 3, 50139 Florence, Italy 

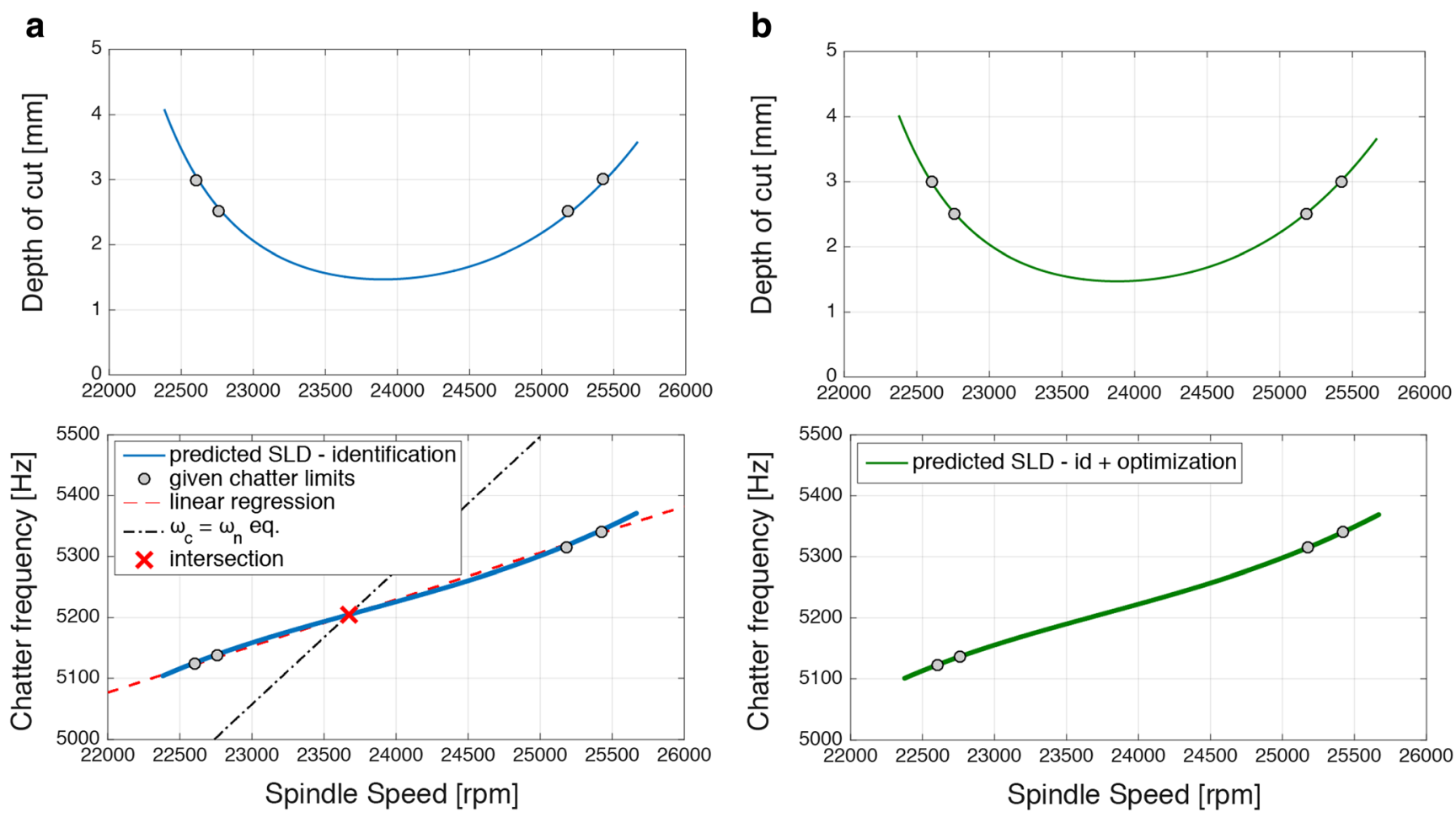

Fig. 4 Numerical validation results: a SLD after identification and b SLD after optimization

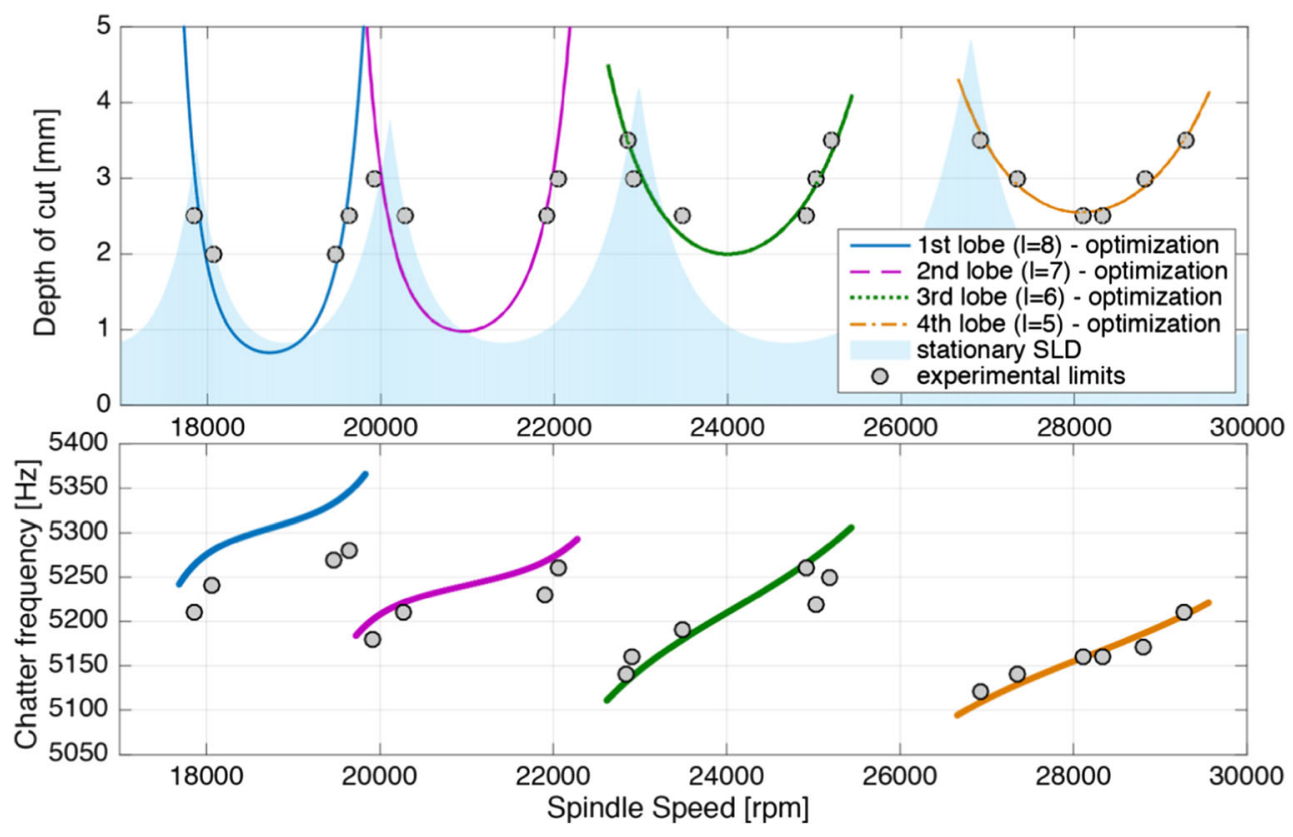

Fig. 8 SLD after optimization for case study A 


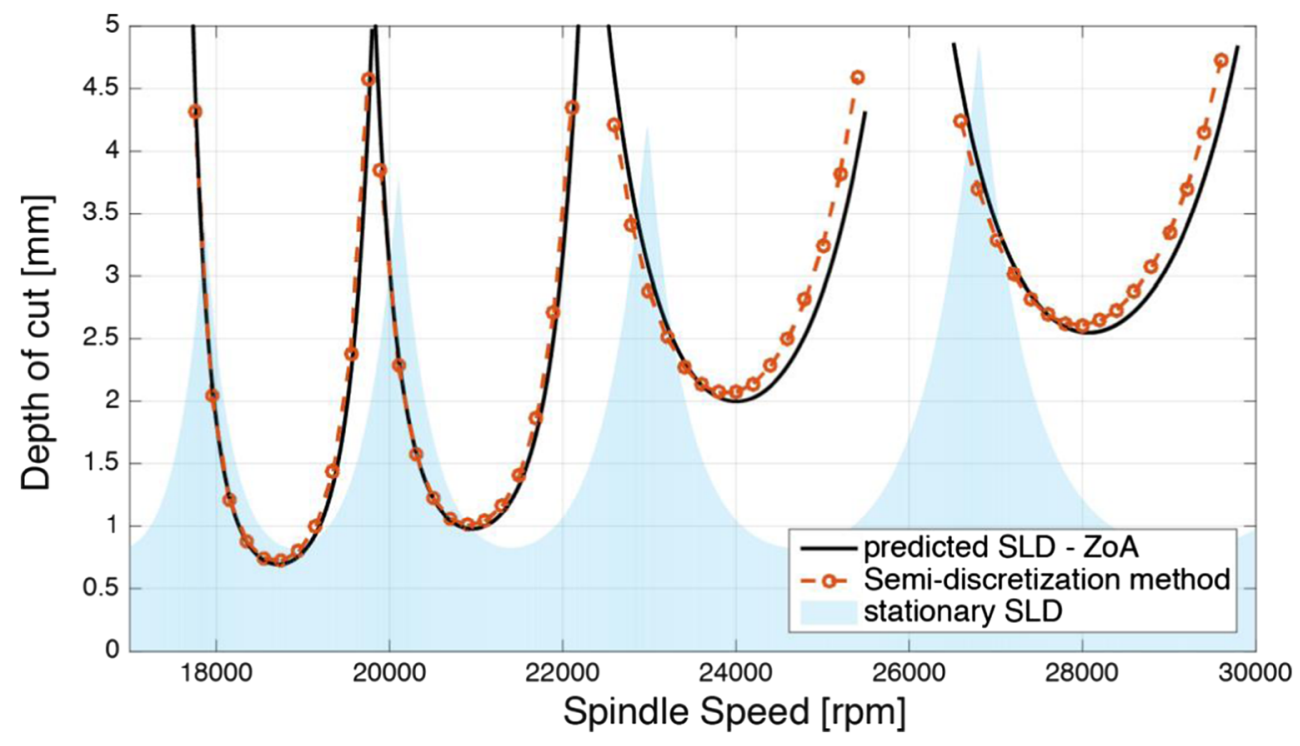

Fig. 10 SLDs computed via ZOA and semi-discretization method

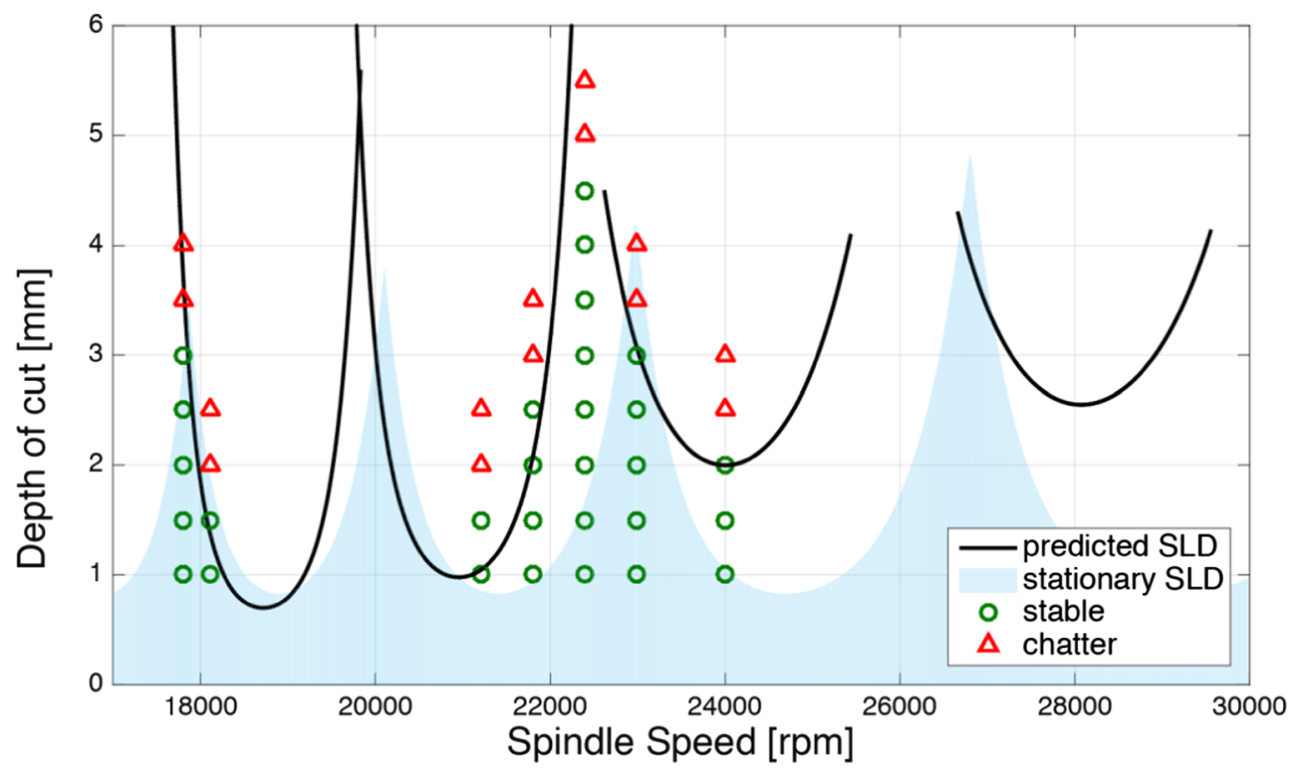

Fig. 11 SLD validation via constant parameter chatter tests 

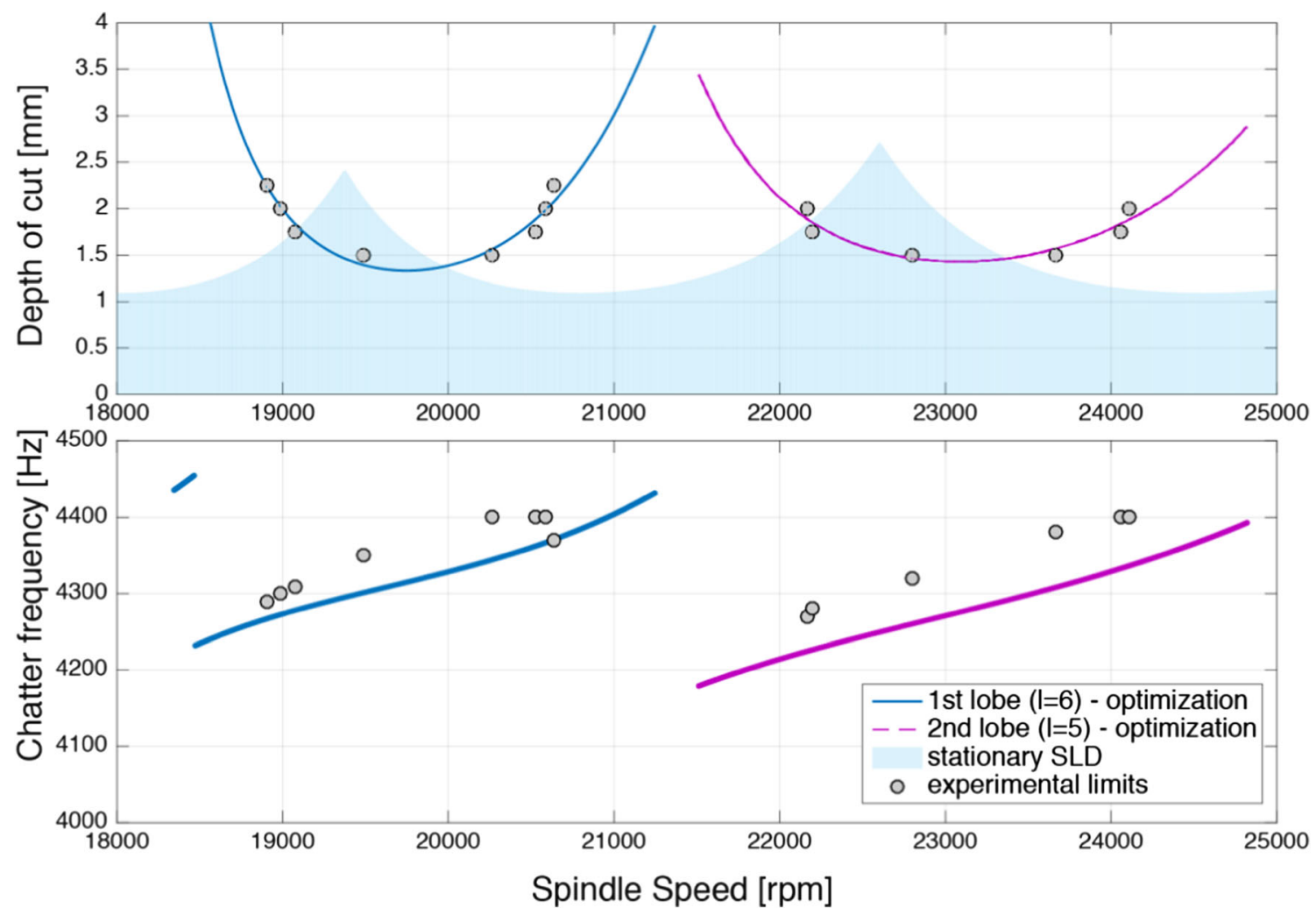

Fig. 13 SLD after optimization for case study B

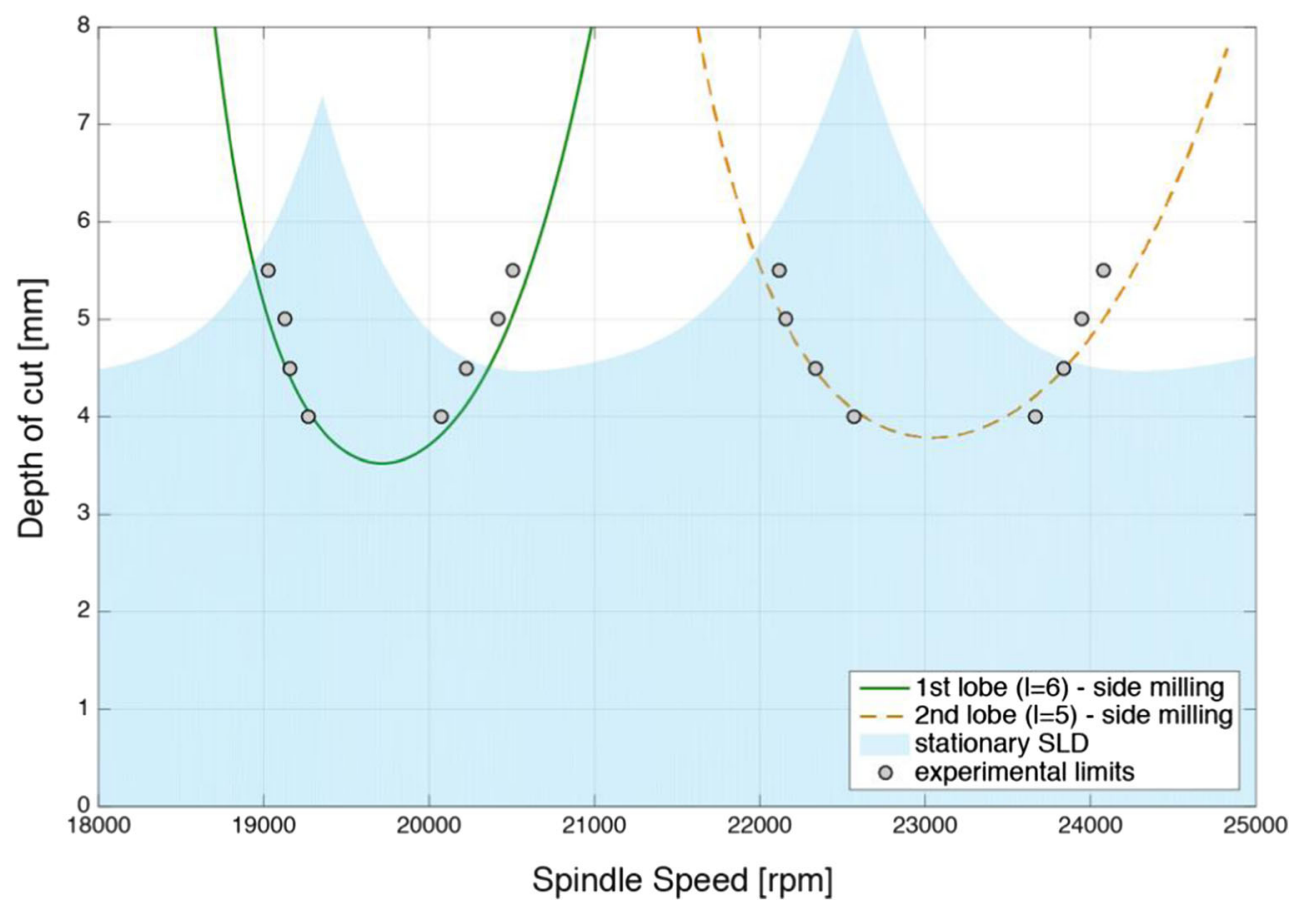

Fig. 15 SLD for half-side milling using tool-tip FRFs extracted with slotting tests 